\title{
Bilateral Basaloid Squamous Cell Carcinoma of the Parotid Gland: A Case Report and Review of the Literature
}

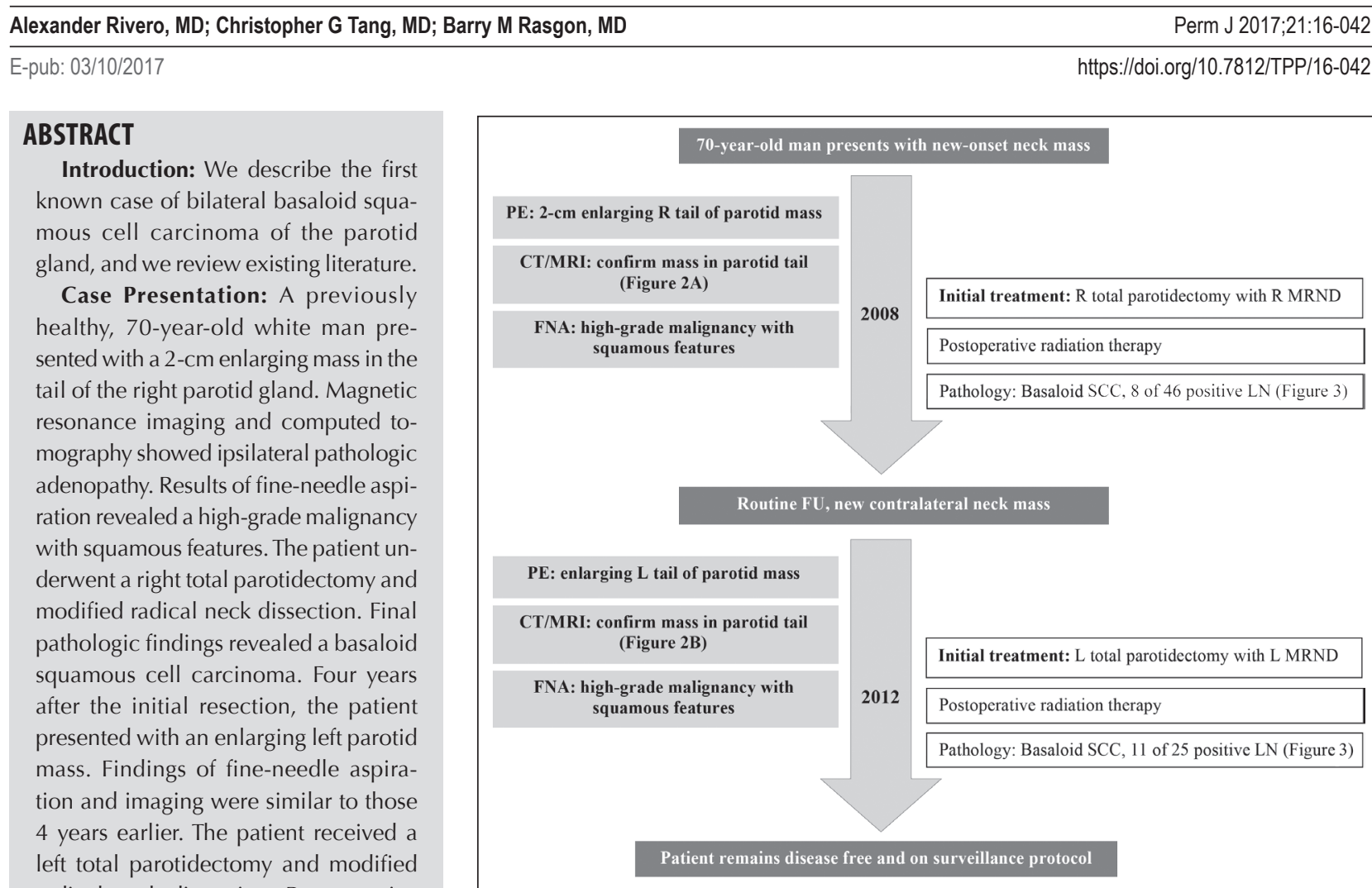
radical neck dissection. Postoperative radiation therapy was performed after each surgical intervention. He remains disease free at 4-year follow-up after the second mass was resected.

Discussion: Squamous cell carcinoma with basaloid features is a rare and aggressive type of squamous cell carcinoma. To our knowledge, this is the first case report of bilateral parotid basaloid squamous cell carcinoma.

\section{INTRODUCTION}

Basaloid squamous cell carcinoma (BSCC) was first described in the head and neck region by Wain et $\mathrm{al}^{1}$ in 1986 and described by Shivakumar in 2014 . $^{2}$ It was originally described as a high-grade variant of traditional squamous cell carcinoma (SCC) and differentiated by its

Figure 1. Timeline of the case.

$\mathrm{CT} / \mathrm{MRI}$ = computed tomography/magnetic resonance imaging; $F N A=$ fine-needle aspiration; $F U$ = follow-up; $\mathrm{L}=$ left; $\mathrm{LN}=$ lymph nodes; $\mathrm{MRND}=$ modified radical neck dissection; $\mathrm{PE}=$ physical examination; $\mathrm{R}=$ right; $\mathrm{SCC}=$ squamous cell carcinoma

characteristic histopathologic findings of a biphasic pattern, including both basaloid and squamous features. BSCC contains sheets and lobules that produce a "jigsaw puzzle" growth pattern with cystic spaces containing periodic acid Schiff-positive myxoid material. ${ }^{3}$ More recent views recognize the dual behavior of BSCC, with both an aggressive behavior noted in laryngeal locations and a more classic (better) prognosis noted in other age- and subsite-matched groups. ${ }^{4}$ Following the CARE guidelines for case reports, ${ }^{5}$ we present a case of bilateral basaloid squamous cell carcinoma of the parotid gland-to our knowledge, the first such case reported in the literature.

\section{CASE PRESENTATION \\ Presenting Concerns}

A 70-year-old, previously healthy white man presented to our clinic with an enlarging mass in the right neck (Figure 1). His medical history was remarkable for multiple skin cancers, albeit none in the face or parotid area. He denied tobacco or alcohol use. His review of symptoms showed no weight loss, night sweats, fatigue, or fever 


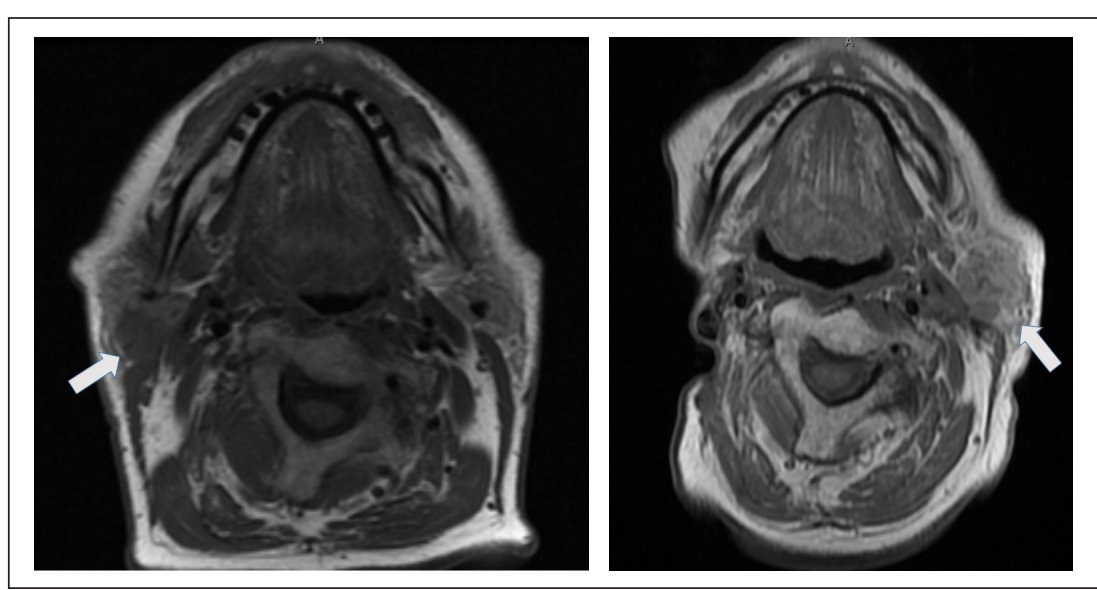

Figure 2. A. (left) Axial T1-weighted magnetic resonance image (MRI) of right parotid lesion in 2008. B. (right) Axial T1-weighted MRI of left parotid lesion 4 years later.

and chills. Physical examination revealed a firm, approximately 2 -cm mass in the right tail of the parotid gland with normal overlying skin. Examination of the facial nerve showed normal function. Magnetic resonance imaging was performed, showing a $15-\mathrm{mm}$, rim-enhancing, noncystic mass in the right tail of the parotid gland and enlarged adenopathy throughout, with a pathologic-appearing lymph node in the right Level 2b (Figure 2A). Fine-needle aspiration of the mass and lymph node revealed a high-grade malignancy with squamous features. A preoperative electrocardiogram and laboratory test results were normal.

The patient received a right total parotidectomy with facial nerve preservation and a right modified radical neck dissection. Final pathologic results are shown in Figure $3 \mathrm{~A}$ and $\mathrm{B}$. Eight of 46 total lymph nodes were positive for metastatic disease. Postoperative radiation therapy was performed.

Four years after the initial resection, the patient presented with an enlarging left parotid mass. A fine-needle aspiration specimen revealed identical pathologic findings of a high-grade malignancy (not pictured) as with the initial mass. Magnetic resonance imaging was performed, showing a similar mass of the parotid tail and pathologic adenopathy on the left side (Figure $2 \mathrm{~B}$ ) as was demonstrated in 2008 on the right side.

\section{Therapeutic Intervention and Treatment}

The patient received a left total parotidectomy with facial nerve preservation and a left-sided extended modified radical neck dissection (with sacrifice of Cranial Nerves 9, 11, and 12 owing to involvement with tumor). Eleven of 25 lymph nodes were positive for metastatic disease.

Postoperative radiation therapy was performed. Given the location in the salivary gland, human papillomavirus (HPV) p16 testing was not performed on either specimen.

\section{Follow-up and Outcomes}

Four years later, our patient remains disease free and on a surveillance protocol.

\section{DISCUSSION}

The World Health Organization defines BSCC as an aggressive and rapidly growing variant of SCC with a propensity for local and distant metastasis. ${ }^{6}$ Fritsch and Lentsch ${ }^{4}$ challenge this definition via their recent Surveillance, Epidemiology, and End Results database review in 2014. When matching for age and subsite, they demonstrated an improved disease-specific survival when BSCC is limited to the oropharynx, worse disease-specific survival when BSCC involves the larynx, and similar disease-specific survival in BSCC of the sinonasal, oral, and hypopharyngeal subsites. ${ }^{4}$ Although the potential difference in prognosis offers no major change in treatment algorithm, it provides more evidence for a discussion with patients regarding ultimate outcomes. BSCC carries similar risk factors of alcohol and tobacco use that SCC does. HPV status also has been investigated in BSCC. Chernock et $\mathrm{al}^{7}$ found that $75 \%$ of oropharyngeal BSCC are HPV related, whereas $0 \%$ of 16 laryngeal and hypopharyngeal tumors
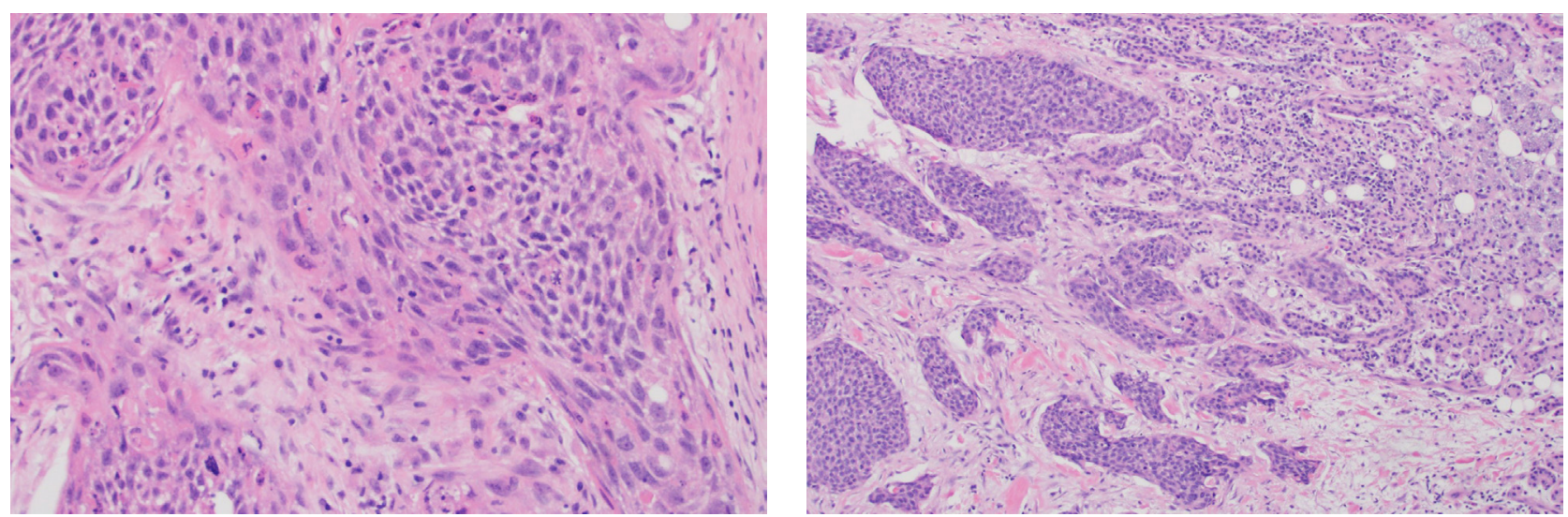

Figure 3. A. (left) Histologic specimen (magnification x100, hematoxylin-eosin stain) in 2008 of basaloid area (upper field) with nuclear-cytoplasmic ratio and of squamous area (lower field) with abundant eosinophilic cytoplasm. B. (right) Infiltrating irregular tumor nests (left) into parotid gland (right) in 2008. Pathologic images from 2012 are unavailable but according to the pathology report were identical to those shown in 2008. 
were positive for HPV. Begum and Westra ${ }^{8}$ had similar findings demonstrating HPV in $76 \%$ of oropharyngeal BSCC and in $6 \%$ of tumors in nonoropharyngeal sites. As has been previously demonstrated in multiple studies, HPV positivity confers an improved prognosis and greater response to all forms of therapy (surgical and medical) for SCC. This seems to also hold true for the BSCC variant.

In a literature review including PubMed and Ovid databases, we could find no reported case of BSCC in the parotid gland. Additionally, there has been no reported case of bilateral disease process in the same patient, making this case unique and interesting. To our knowledge, no specific treatment management of BSCC in the salivary gland has been described. The treatment of BSCC in all other described subsites of the head and neck is the same as its SCC counterpart, usually involving surgical excision of the tumor (if amenable to excision) with associated neck dissection with or without adjuvant radiation therapy. We cannot speculate why this patient had bilateral disease. However, given his history of multiple skin cancers, it may be that he had a genetic predisposition to neoplastic transformation. The left-sided disease that presented four years after initial disease on the contralateral side was treated as a second primary cancer. This may, however, represent a metastatic focus. That said, it would be uncommon to have metastasis to the parotid gland as the first site.

\section{CONCLUSION}

This is a unique case of BSCC of the parotid gland. SCC with basaloid features is a rare variant of SCC with both aggressive and indolent characteristics depending on the head and neck subsite. Similar to SCC, typical risk factors in BSCC include alcohol consumption and tobacco use. HPV positivity in BSCC confers an improved prognosis. To date, our patient remains disease free four years after surgery and postoperative radiation therapy. To our knowledge, this is the first case report of bilateral parotid BSCC.

\section{Disclosure Statement \\ The author(s) have no conflicts of interest to disclose.}

\section{Author Contributions}

The principal investigator, Alexander Rivero, MD, had full access to all the data in the study and takes full responsibility for the integrity of the data and the accuracy of the data analysis. All authors were involved in the development of the manuscript. Christopher G Tang, MD, and Barry M Rasgon, MD, were involved in the care of the patient.

\section{Acknowledgments}

This work was presented as a scientific poster at the Combined Sections Meeting of the Triological Society, San Diego, CA, January 2015.

Kathleen Louden, ELS, of Louden Health Communications provided editorial assistance.

\section{How to Cite this Article}

Rivero A, Tang CG, Rasgon BM. Bilateral basaloid squamous cell carcinoma of the parotid gland: A case report and review of the literature. Perm J 2017;21:16-042. DOI: https://doi.org/10.7812/ TPP/16-042.

\section{References}

1. Wain SL, Kier R, Vollmer RT, Bossen EH. Basaloidsquamous carcinoma of the tongue, hypopharynx, and larynx: Report of 10 cases. Hum Pathol 1986 Nov;17(11):1158-66. DOI: https://doi.org/10.1016/ S0046-8177(86)80422-1

2. Shivakumar B, Dash B, Sahu A, Nayak B. Basaloid squamous cell carcinoma: A rare case report with review of literature. J Oral Maxillofac Pathol 2014 May-Aug;18(2):291-4. DOI: https://doi. org/10.4103/0973-029x.140797.

3. El-Mofty SK. Histopathologic risk factors in oral and oropharyngeal squamous cell carcinoma variants: An update with special reference to HPV-related carcinomas. Med Oral Patol Oral Cir Bucal 2014 Jul;19(4):e377-85. DOI: https://doi.org/10.4317/ medoral.20184.

4. Fritsch VA, Lentsch EJ. Basaloid squamous cell carcinoma of the head and neck: Location means everything. J Surg Oncol 2014 May;109(6):616-22. DOI: https://doi.org/10.1002/jso.23536.

5. Gagnier JJ, Kienle G, Altman DG, Moher D, Sox H, Riley D; CARE Group. The CARE guidelines: Consensus-based clinical case report guideline development. J Clin Epidemiol 2014 Jan;67(1):46-51. DOI: https://doi.org/10.3109/19390211.2013.830679.

6. Barnes C, Eveson JW, Reichart P, Sidransky D, editors. Pathology \& genetics. Head and neck tumours. World Health Organization classification of tumours. Lyon, France: IARC Press; 2005.

7. Chernock RD, Lewis JS Jr, Zhang Q, El-Mofty SK. Human papillomavirus-positive basaloid squamous cell carcinomas of the upper aerodigestive tract: A distinct clinicopathologic and molecular subtype of basaloid squamous cell carcinoma. Hum Pathol 2010 Jul;41(7):1016-23. DOI: https://doi.org/10.1016/j. humpath.2009.11.015.

8. Begum S, Westra WH. Basaloid squamous cell carcinoma of the head and neck is a mixed variant that can be further resolved by HPV status. Am J Surg Pathol 2008 Jul;32(7):1044-50. DOI: https://doi. org/10.1097/pas.0b013e31816380ec 